\title{
Smoke Movement Characteristics and Fire Safety in Subway Stations
}

\author{
SHUJI MORIYAMA, YUJI HASEMI, DON-GUN NAM, SATOSHI TANAKA, \\ NAOMI OKAZAWA, and WENTING DING \\ Department of Architecture \\ Waseda University \\ Tokyo, 169-8555, Japan
}

\begin{abstract}
Experimental and numerical studies on smoke movement and control in subway stations are presented. The experiments were conducted in three actual stations in service using small methanol pool fires as the fuel to generate data basis to validate and tune numerical models for subway station fires and furthermore to examine the performance of smoke control systems. A control volume smoke movement model has been applied to the stations. The model was first tuned to reproduce the test results for the simplest condition for each station, and was then applied and compared with test results for other test conditions. The model was finally applied to predict smoke movement in the subway stations of more plausible fires. The effective design and functional operation of fire safety measures in subway systems are discussed. Primarily, importance of restriction of heat release rate through either the control of combustibility of lining materials or installation of sprinkler system is pointed out. And it is clarified that arrangement of alternative evacuation routes on either ends of the platform, and appropriate operation of shutters in stairways between the platform and the concourse ensure safe evacuation.
\end{abstract}

KEYWORDS: smoke movement, subway station, experiments and numerical studies, safety evacuation

\section{INTRODUCTION}

The subway train and station fire in Daegue, Korea, on 18 February, 2003, revealed significant hazard in case of a fire in underground railway systems. While underground railway systems are common in many big cities in the world and employ some fire safety measures according to local regulations in general, it is believed that there is not always solid technical background for the effectiveness of these fire safety measures. Few experiments or modeling works have been conducted on smoke movement, fire growth and human behavior in underground railway train stations, although the rather low ceiling of stations and high fire load in train and the connection of a station to a tunnel are thought to be disadvantageous for the restriction of fire spread or the effective smoke control. This should call attention of transportation authorities and fire experts to revisit the effectiveness of the current fire regulations on subway systems world wide to establish effective fire safety measures. In Japan, each of Railway Bureau of the Ministry of Land Infrastructure Management (MLIT) and Tokyo Fire Department (TFD) independently set up projects on the fire safety of subway systems after the Daegue subway fire. As a part of the TFD's project, which focused on the fire fighting strategy in the event of a subway fire, smoke experiments were conducted using actual subway stations in service in Tokyo. The experiments aimed at establishing database for the development of predictive models for subway fires, and examining performance of 
existing fire safety measures in subway systems. A brief summary of these experiments and numerical studies is introduced in this paper.

\section{SMOKE TESTS IN SUBWAY STATIONS}

In April 2003, TFD organized an experts committee on subway fires. Considering the lack of experimental knowledge on subway fires, it was decided to conduct fire tests in subway stations in service to clarify the control mechanism of smoke flow in subway stations under the cooperation with the Teito Rapid Transit Authority (TRTA, "Eidan Subway, privatized and renamed as "Tokyo Metro" in April 2004) and the Transportation Bureau of the Tokyo Metropolitan Government ("Toei” subway), the two subway operating bodies in Tokyo.

Smoke movement tests were conducted using simulated fire sources on the platform in three subway stations currently in service in Tokyo in October 2003. Two most typical layouts of platforms in subways stations, Center platform type station and Side platform type station, see Figs. 1a and 1b, were chosen. Both types were chosen from Eidan Subway line, and a Centre platform type station was chosen from Toei Subway line. These stations will be referred to Center platform A, Side platform B (both from Eidan Subway), Center platform C (Toei Subway) respectively. The platform of every selected station is located on the B-2 level, and is connected by stairways and escalators to a concourse on the B-1 level. Every station is equipped with ventilation system for the platform which can be used for smoke extraction by reversing the fan. The tests were conducted at midnight to avoid conflicts with the traffic services. While numerous scenarios are conceivable on fire and on operation of fire safety measures, the contents of the tests were limited to those shown in Table 1 for extremely restricted time available for each test. Operation of smoke extraction system and the fire shutters in the stairway connected the platform and the concourse was the major experimental parameters. Shutters are normally kept open during the fire fighting activity until the evacuation from the platform is completed in order to prevent smoke ingress to the concourse and not to block the evacuation from platform. Shutters and doors connecting to the basements of adjacent buildings were closed to simplify the test conditions.

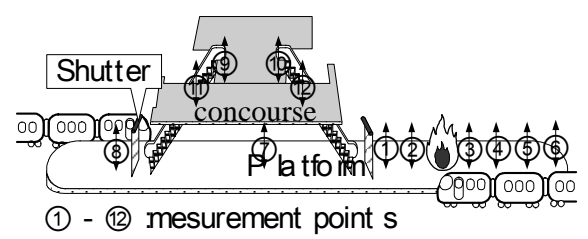

(a) Center platform.

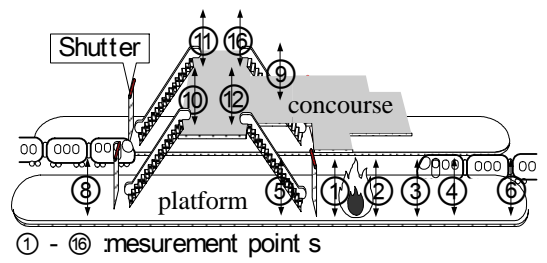

(b) Side platform.

Fig. 1. Two types of platform.

Fire sources were simulated with methanol in 2 or $60.50 \mathrm{~m}$ square trays. According to preliminary tests, it had been confirmed that each tray has approximately $80 \mathrm{~kW}$ heat release rate. The fire source intensities were chosen not to cause any damage to stations according to the anticipated fragility of each subway stations, i.e., $160 \mathrm{~kW}$ for Center platform C station and $480 \mathrm{~kW}$ for other two stations. Since this heat release rate represents only the early stage of a growing fire, it was planned to use numerical simulations to predict impact of more plausible fires. The present tests were conducted to 
provide information to validate such model and more directly to study the effectiveness of the smoke control systems designed according to the current Japanese regulations.

Table 1. Smoke movement test condition.

\begin{tabular}{|c|c|c|c|}
\hline Series & Fire Source & Mechanical Smoke Exhaustion & $\begin{array}{c}\text { Fire shutters on the Stairway } \\
\text { between } \\
\text { Platform and Concourse }\end{array}$ \\
\hline$\overline{1}$ & & off & open \\
\hline 2 & \multirow{3}{*}{$\begin{array}{l}\text { methanol } \\
\text { pans on } \\
\text { platform }\end{array}$} & off & closed, half open*, open \\
\hline 3 & & on,platform & closed, half open*, open \\
\hline 4 & & on,both platform and concourse & closed, half open*, open \\
\hline
\end{tabular}

*: Set the bottom edge of the shutters down to the position of $50 \mathrm{~cm}$ below the ceiling

Distribution of temperature, velocity and static pressure throughout the platforms, the tunnel, and concourse were measured. K-type thermocouples, hot-wire velocity probes, pressure tubes and other probes were set on length-adjustable poles. Hot gas movement was visualized with smoke candles located near the fire source. Figure 2 shows a typical measurement layout. The interior linings and columns near the fire source were protected with flexible noncombustible sheet.

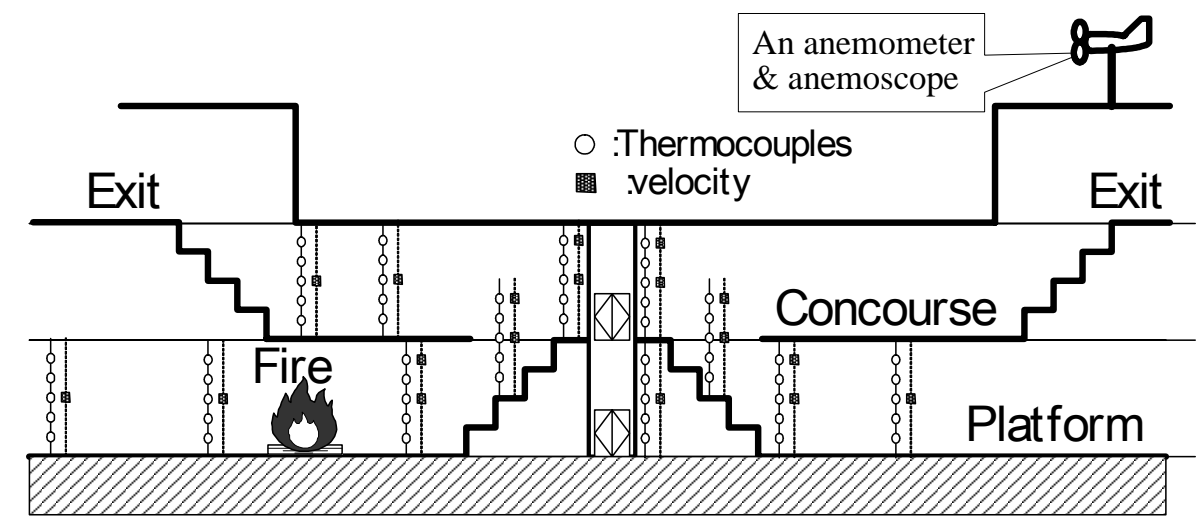

Fig. 2. Measurement layouts, smoke movement tests at subway stations.

\section{EXPERIMENTAL RESULTS, SUMMARY}

This paper only reports the experimental and the numerical results of Center platform A station, which is the most typical platform of Subway station. Smoke extraction fan of this station has $130,740 \mathrm{~m}^{3} / \mathrm{h}$ capacity according to the A-A standard, which is the Japanese fire regulation for underground railway systems, and prescribes the required rate of air ventilation according to the volume of platforms. Figure 3 is a summary of the test results. Number in each circle indicates the location of the thermocouple/probe pole, which is found in (a) Plan and measurement layout. The reported temperatures and velocities are time-averaged value of the test data after the temperature field had reached steady state in each test. From the test results, following summaries can be drawn on the general characteristics in the smoke movement and the smoke control performance in the subway station. Operation of shutters was found to cause significant influence on the smoke movement. The air flow blowing down the stairway to the tunnel with the shutters open can prevent smoke penetration from the platform to the concourse, but at the same 
time, strong wind through the stairway destabilizes the smoke layer above the platform, which causes the wide area of the platform to be significantly contaminated by smoke.

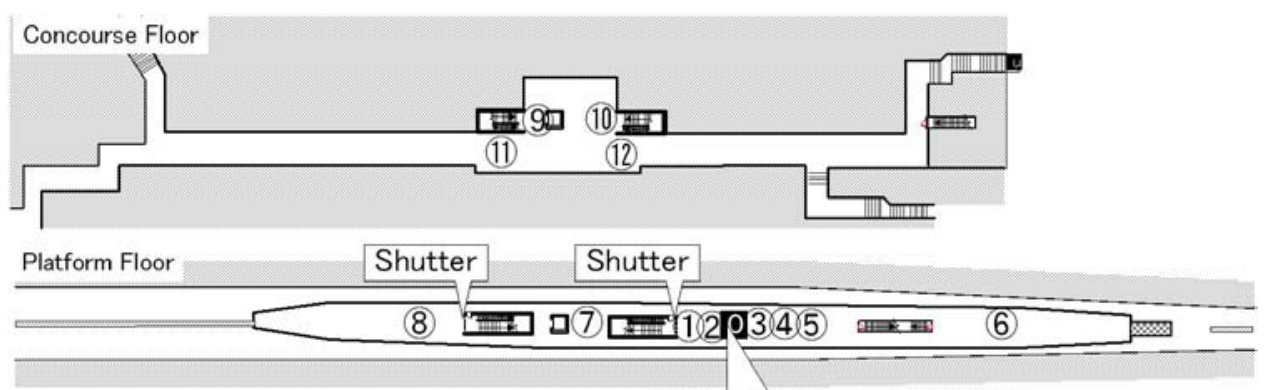

Fire source, approx.480kW

(a) Plan and measurements layout.
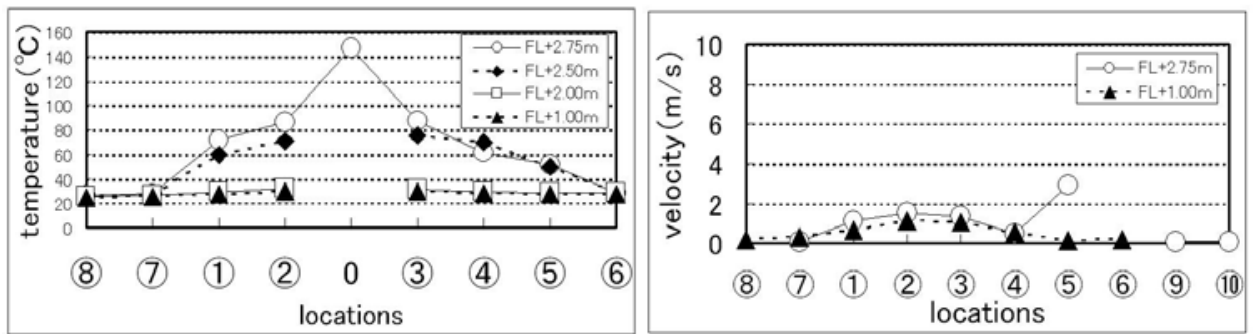

(b) Temperature and velocity, shutters CLOSED, smoke extraction OFF.
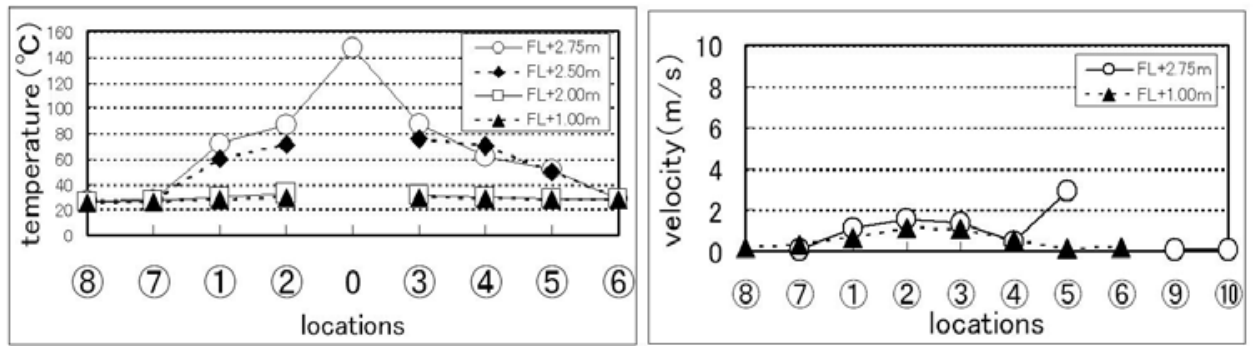

(c) Temperature and velocity, shutters CLOSED, smoke extraction ON.
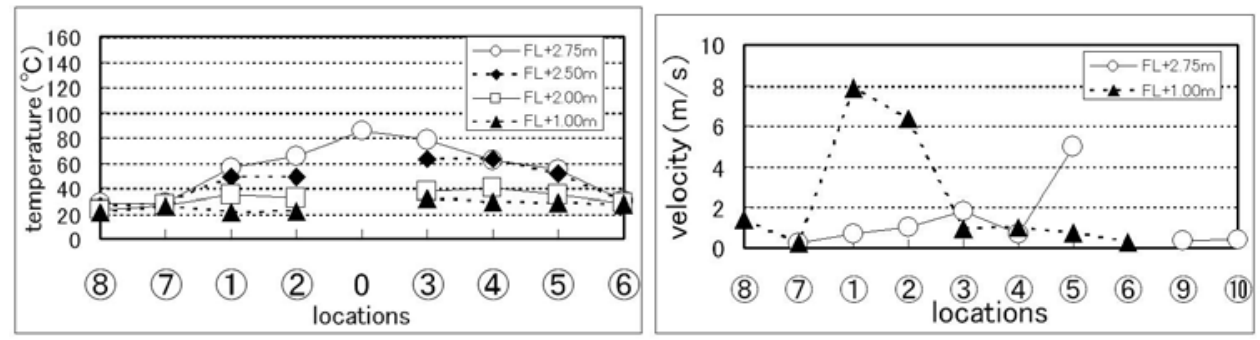

(d) Temperature and velocity, shutters OPEN, smoke extraction ON.

Fig. 3. Summary test results, center platform-A station. 
This effect is particularly strong when the smoke extraction is operated in the platform. Smoke layer on the platform level is kept stable as long as the shutters were closed. Smoke extraction on the platform level can maintain smoke layer at height enough to prevent people from being exposed to smoke. With the smoke extraction on the platform level operated and the shutters closed in the center platform, accumulation of thick smoke layer can be restricted within the fire area confined by the stairways.

\section{NUMERIACL STUDY BY CONTROL VOLUME MODEL}

Numerical studies were carried out to reproduce the experiments and then to predict fire hazard and evaluate effectiveness of such fire safety measures as smoke extraction and fire shutters in the event of more plausible, severe, fires. The model is essentially based on a zone model, but some minor modifications were made to deal with the leeward changes of smoke layer depth within the platform and concourse. The modification includes subdivision of the platform to reproduce gradual development of smoke layer from the fire source toward both ends of the platform. The model was first tuned using the test data on a simplest condition with the shutters closed and the smoke extraction off. The model was then validated against other test conditions. Finally the model was applied to predict a $20 \mathrm{MW}$ fire on the platform, whose intensity was determined according to burn tests on a subway train and a station-shop in recent Japan railway stations.

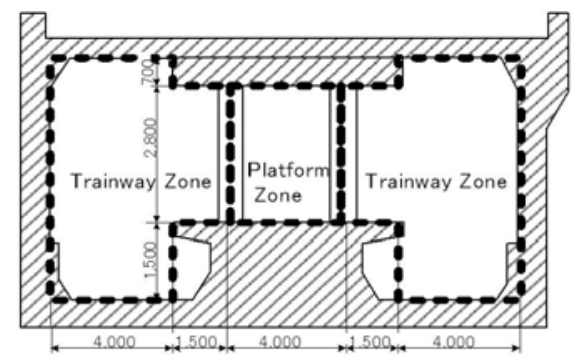

(a) Section of center platform station $\mathrm{A}$.

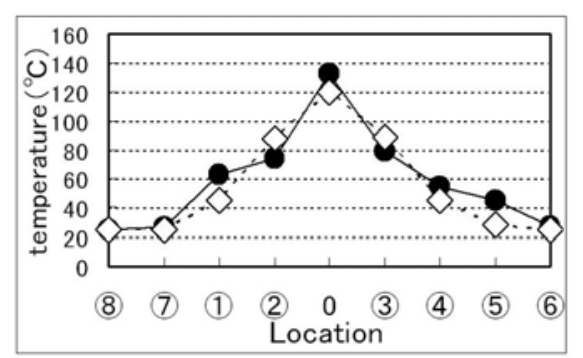

(b) Shutters: CLOSED, Smoke extraction: OFF.
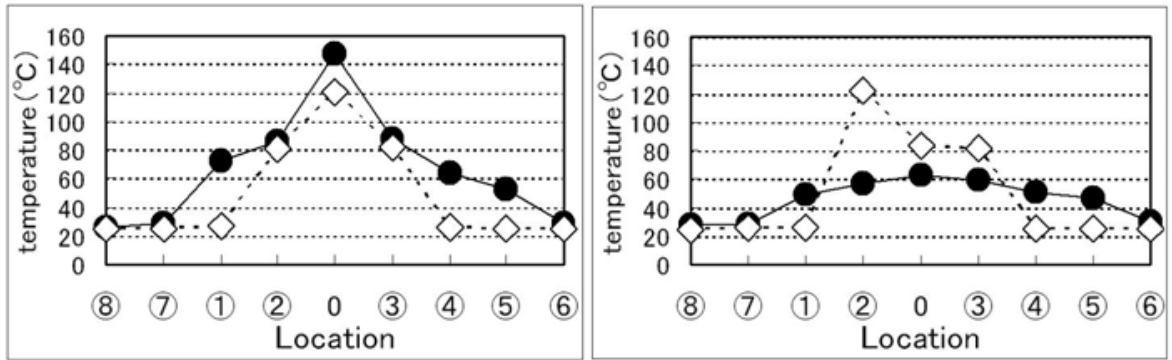

(c) Shutters: CLOSED, Smoke extraction: ON.(d) Shutters: OPEN, Smoke extraction: ON.

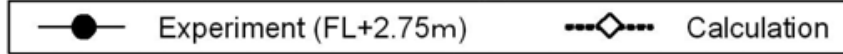

Fig. 4. Experimental and numerical smoke layer temperatures.

\section{VALIDITY OF THE MODEL}

Figure 4 summarizes the numerical results of the smoke layer temperature in Center platform station A. As observed in the experiments, smoke movement in a subway station 
is highly dependent on the conditions of the shutters between the platform and the concourse. Since the smoke layer was the most stable when the shutters were closed, the model was tuned against the test data for the simplest condition, i.e., with the shutters Closed and the smoke extraction OFF (Fig. 4b). The results suggest that the numerical model can reproduce experiment as long as the shutters are closed (Fig. 4c), whereas smoke layer temperature near the fire source was generally overestimated for the conditions with shutters left OPEN (Fig. 4d). This overestimate of the smoke layer temperature by calculation is particularly notable when the smoke extraction is operated. Overestimate of smoke layer temperature implies an underestimate of the mixing of the smoke into the lower layer, which may further result in the underestimate of the hazard under specific fire scenarios. This discrepancy is attributed to the limited capability of the model, or any zone type fire model, to reproduce the destabilization of the smoke layer due to the air supplied through the stairway.

\section{NUMERICAL RESULTS OF A 20 MW FIRE FOR SEVERAL PLATFORMS}

According to the burn tests in actual subway trains and station-shops conducted parallel with but independently from the present project, maximum heat release rate due to a single burning of a train compliant with the current Japanese regulations was in the range of 10-20 MW [3,4], and typical heat release rate due to a fire of a shop common in Japanese train stations was around 5-15 MW [5]. In order to understand the magnitude of fire hazard caused by such plausible fire sources, numerical studies were conducted for a 20 MW fire for the two most typical layouts of stairways on the center platform, stairways on the center of the platform (Center stairways platform), stairways on the both-ends on the platform (Both-ends stairways platform). Figure 5 shows the validity of extrapolation for large fire of this model. According to the increase of fire intensity, heights of smoke layer interface fall down and temperatures of smoke layer rise up (location is shown in Fig. 7a). Only the height of smoke layer of point 18 for 20 MW, falls down to floor level almost. It is thought that temperature of the whole space of point 18 is equal to the temperature of lower layer on the neighboring trainway zone which rises up to 35 degree C. Two types of fire sources were adopted for numerical studies, a steady fire source was applied to identify the effects of shutters and smoke extraction, a growing fire source was adopted for validate the evacuation related with smoke movement characteristics.
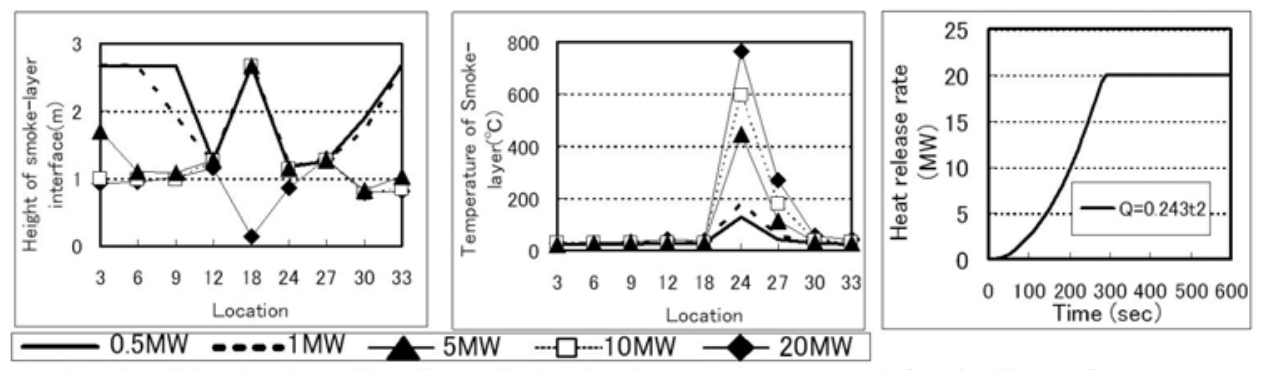

(a) Height of smoke layer interface. (b) Smoke layer temperature.

Fig. 5. Numerical results of various steady fire sources, center-stairs platform.

Fig. 6. Heat release rate of growing fire source. 
Table 2. Scenarios of evacuation [6].

\begin{tabular}{|c|c|c|c|}
\hline & $\begin{array}{l}\text { Equations for calculation of } \\
\text { evacuation times [6] }\end{array}$ & $\begin{array}{c}\text { Center } \\
\text { stairways } \\
\text { platform }\end{array}$ & $\begin{array}{l}\text { Both-ends } \\
\text { stairways } \\
\text { platform }\end{array}$ \\
\hline Platform area & Ap & \multicolumn{2}{|c|}{$1,470 \mathrm{~m}^{2}$} \\
\hline Occupant load for the platform & $\mathrm{P}$ & \multicolumn{2}{|c|}{$\begin{array}{c}1,800 \text { persons } \\
(150 \text { pesons } \times 8 \text { cars } \times 150 \%)\end{array}$} \\
\hline Travel speed & $\mathrm{V}$ & \multicolumn{2}{|c|}{$1.0 \mathrm{~m} / \mathrm{sec}$} \\
\hline \begin{tabular}{|l|l} 
Capacity of exit & entrance of \\
\end{tabular} & $\mathrm{Ne}$ & \multicolumn{2}{|c|}{1.5 person/(sec $\cdot \mathrm{m})$} \\
\hline \begin{tabular}{l|l} 
Widths & stairways \\
\end{tabular} & We & \multicolumn{2}{|c|}{$1.5 \mathrm{~m}$} \\
\hline $\begin{array}{l}\text { Length of longest exit route } \\
\text { (to the stair in service) }\end{array}$ & $\mathrm{L}$ & $120 \mathrm{~m}$ & 220m \\
\hline Time to start of evacuation & $\mathrm{Ts}=2 \sqrt{ } \mathrm{Ap}$ & \multicolumn{2}{|c|}{$\frac{1}{77 \mathrm{sec} \text { (after ignition) }}$} \\
\hline Time to clear platform & $\mathrm{Te}=\mathrm{Ts}+\mathrm{MAX}(\mathrm{L} / \mathrm{V}, \mathrm{P} /(\mathrm{Ne} \cdot \mathrm{We}))$ & \multicolumn{2}{|c|}{$880 \mathrm{sec}$ (after ignition) } \\
\hline
\end{tabular}

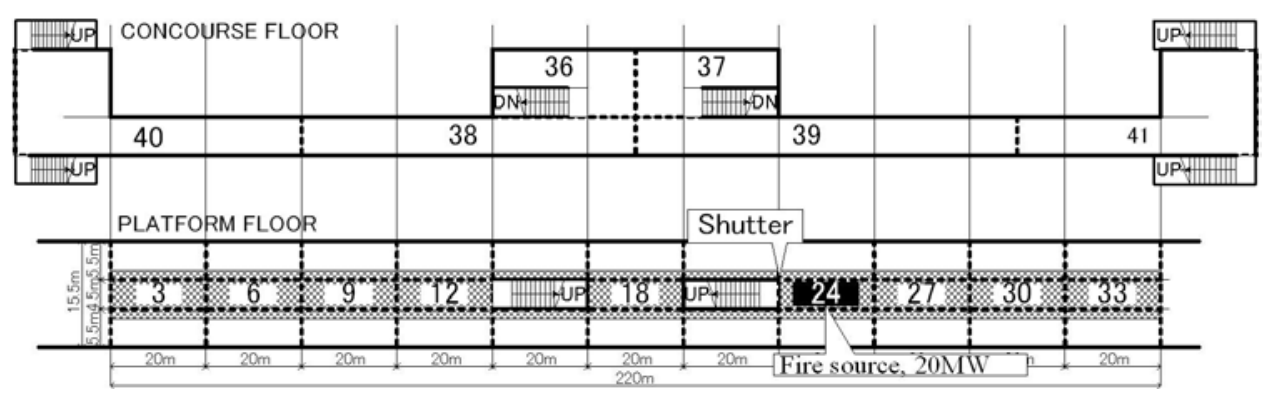

(a) Plan and location.
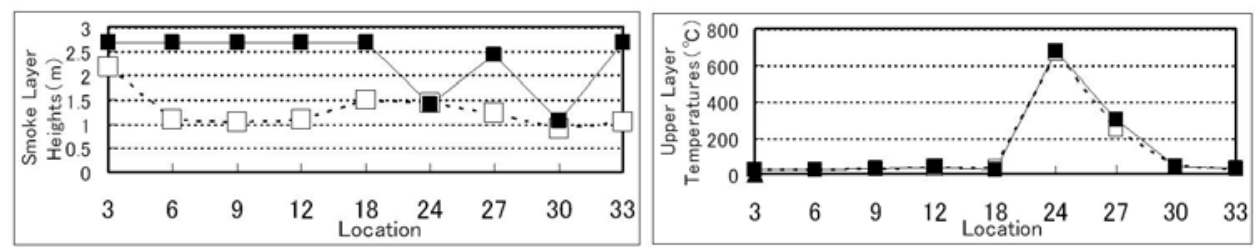

(Platform Floor: Steady Fire Source, shutters OPEN).

--口-- Platform smoke extraction : OFF Platform smoke extraction : ON

(b) Height of smoke layer interface.

(c) Smoke layer temperature.
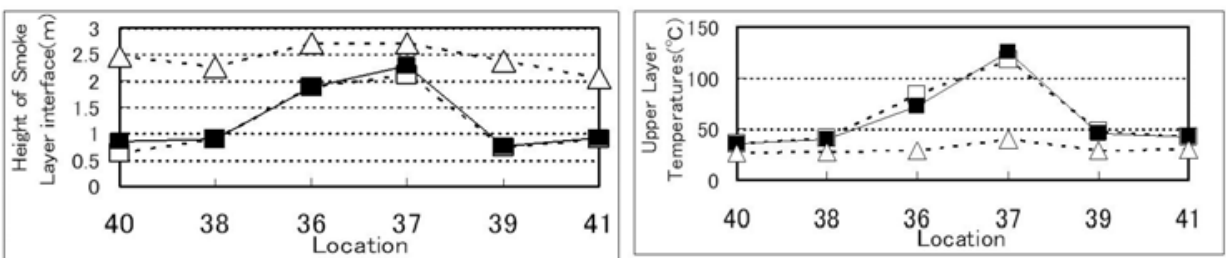

(Concourse Floor: Steady Fire Source)

$\cdots \square-$ Platform smoke extraction : ON, Shutters OPEN

Platform \& Concourse smoke extraction : ON, Shutters OPEN

- Platform \& Concourse smoke extraction : ON, Shutter near by a Fire CLOSED

$\begin{array}{ll}\text { (d) Height of smoke layer interface. } & \text { (e) Smoke layer temperature. }\end{array}$

Fig. 7. Numerical results, $20 \mathrm{MW}$ fire source, center-stairs on the center platform. 

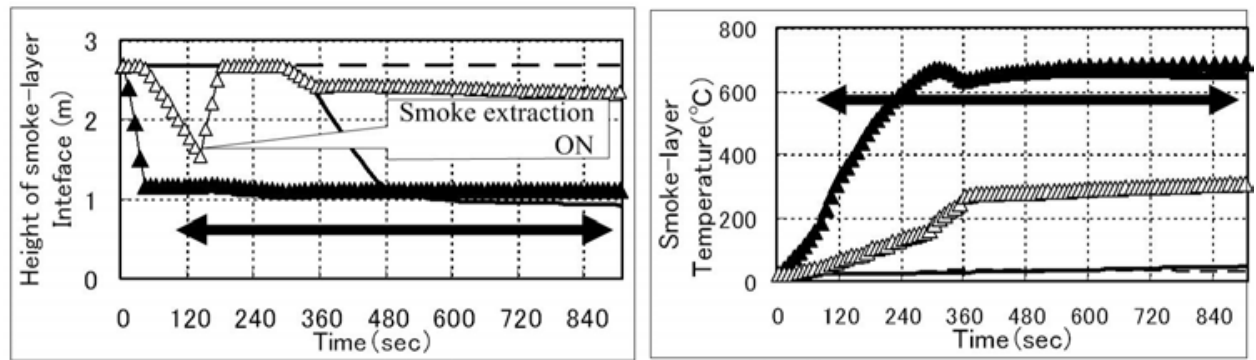

(Platform Floor: Growing Fire Source)

$\cdots$ No.12 No No.24 $\neg$ No.27

(a) Height of smoke layer interface related with evacuation scenarios.

(b) Smoke layer temperature related with evacuation scenarios.

Fig. 8. Numerical results, $20 \mathrm{MW}$ fire source, center-stairs on the center platform.

In case of a growing fire source, shutter nearby the fire is assumed to be closed just after the evacuation from the platform started in order to prevent smoke from going up to concourse and disturb the smoke layer on the platform. Fig. 6 shows the heat release rate of growing fire source. Table 2 shows the equations for calculation of evacuation times and the scenarios of evacuation [6].

Figure 7a shows the plan and the location point of the center stairways platform. Open stairways are provided on the center of the platform. Widths of entrance of stairways are $1.5 \mathrm{~m}$ wide respectively. The platform occupant load is 1,800 persons. According to Table 2, the time to start of evacuation is found to be $77 \mathrm{sec}$, the time to clear the platform is found to be 880 sec after the fire occurred. Smoke extraction fan in the platform is assumed to start after about $60 \mathrm{sec}$ from the time to start of evacuation. Shutter nearby the fire is assumed to be closed at 79 sec after the fire occurred.

Figures $7 \mathrm{~b}-7 \mathrm{e}$ are summaries of calculation results for the center stairways platform for the steady fire source. From the calculation results, following observations can be pointed out. With the smoke extraction on the platform level in the Center stairways platform, accumulation of thick smoke layer can be restricted within the fire area confined by the staircases. Temperature of smoke layer near the fire source generally exceeds 600 degree C by steady fire source (Fig. 7c). Smoke extraction can lift the smoke layer interface by roughly $2.0 \mathrm{~m}$ (Fig. $7 \mathrm{~b}$ ).

The whole concourse is almost exposed with thin smoke when the shutters are open (Figs. 7d, 7e). Smoke extraction cannot lift the smoke layer interface. Height of smoke layer interface falls down to $1.0 \mathrm{~m}$ far from the stairways to the platform, and temperature of smoke rises up to about 40 degree $\mathrm{C}$ far from the stair in the concourse with shutters open and smoke extraction on (point 38, 39, 40 and 41). Height of smoke layer interface nearby the stairs stays around $2.0 \mathrm{~m}$. However, temperature of smoke layer nearby the stairs exceeds 100 degree $C$ (point 36, 37). Smoke is pulled up from the platform. Closure of shutter nearby the fire source and operation of smoke extraction lift the smoke layer interface up to $2.5 \mathrm{~m}$ approximately, and lower the temperature all over the concourse. Operation of the shutters affects significantly the smoke spread to concourse.

Figures $8 \mathrm{a}, 8 \mathrm{~b}$ are summaries of calculation results for the growing fire source, they can be described related with evacuation scenarios. After $40 \mathrm{sec}$ since the fire occurred, height of smoke layer interface falls down to $1.1 \mathrm{~m}$, and the smoke temperature rises up 
to about 100 degree $C$ nearby the fire source (point 24). It is hard to escape passing by the side of the fire source in a short time. While height of smoke layer interface a little away from the fire source falls down to $1.5 \mathrm{~m}$ after $130 \mathrm{sec}$ since the fire occurred, it is lifted up to about $2.5 \mathrm{~m}$ with smoke extraction fan on. However, temperature of smoke rises up to 300 degree $\mathrm{C}$ after $300 \mathrm{sec}$ since the fire occurred, consequently, radiative flux from the smoke layer to any people beneath the smoke layer may exceed the tolerance criteria, e.g., approximately $2.0 \mathrm{~kW} / \mathrm{m}^{2}$. Temperature rises in the lower air layer zone near the fire source can reach 10-30 K, which together with the radiation from the smoke layer could torture evacuees in the vicinity of the fire (point 27). Height of smoke layer interface, where the edge of fire side platform is, falls down to about $1.0 \mathrm{~m}$ after 480 sec since the fire occurred. Temperature of smoke layer exceeds 40 degree $C$ approximately, after 660 sec since the fire occurred (point 30). Especially, when a severe fire breaks out near by a stairway, it is hard to make evacuation safe from the fire side platform to the concourse and hard to stay in the fire side of center stairs platform for long time. This suggests general effectiveness of the provision of alternative evacuation routes on both ends of a platform.

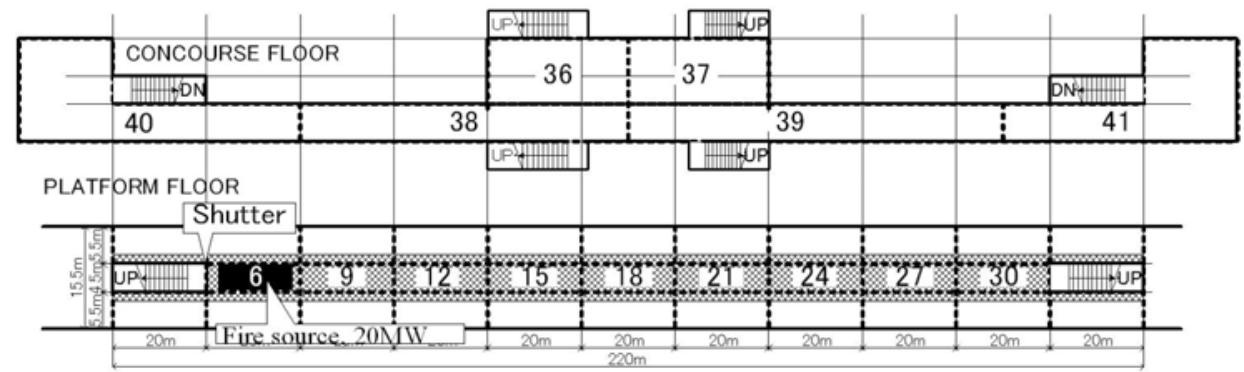

(a) Plan and location.
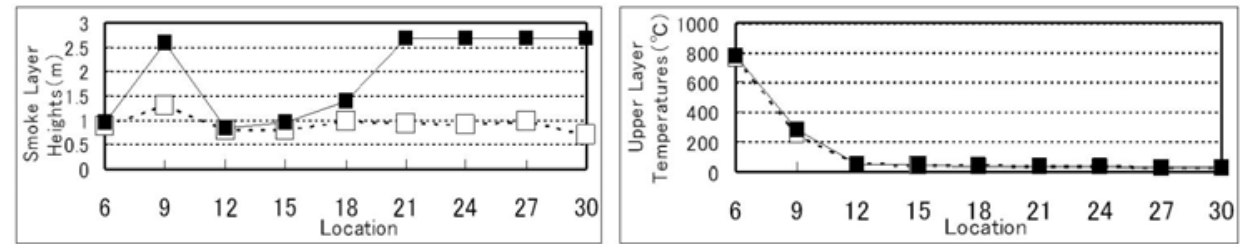

(Platform Floor: Steady Fire Source, shutters OPEN)

--- $\square$ - Platform smoke extraction : OFF Platform smoke extraction : ON

(b) Height of smoke layer interface.

(c) Smoke layer temperature.
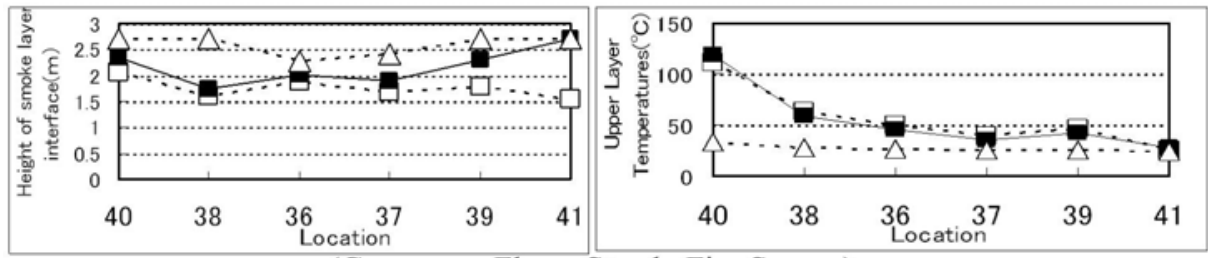

(Concourse Floor: Steady Fire Source)

- - Platform smoke extraction : ON, Shutters OPEN

Platform \& Concourse smoke extraction : ON, Shutters OPEN

- Platform \& Concourse smoke extraction : ON, Shutter near by a Fire CLOSED

(d) Height of smoke layer interface.

(e) Smoke layer temperature.

Fig. 9. Numerical results, $20 \mathrm{MW}$ fire source, both-ends stairs on the center platform. 

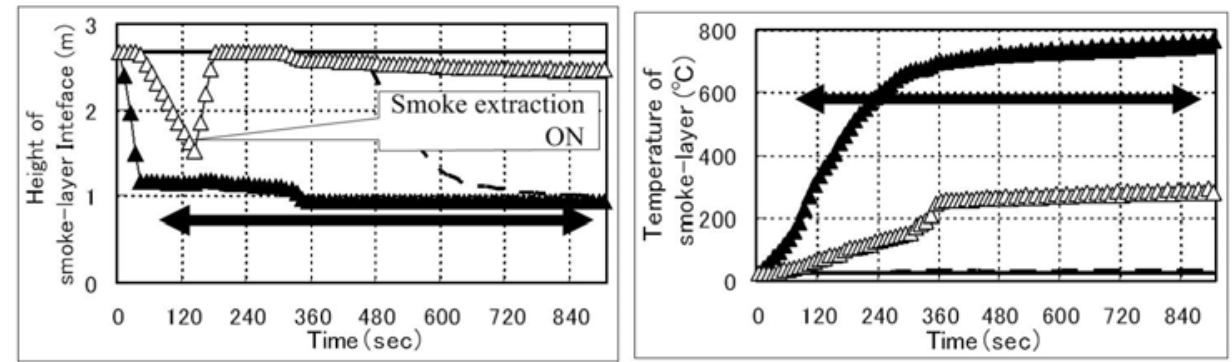

(Platform Floor: Growing Fire Source)

\section{$\cdots$ No.12 No.6 No.9}

(a) Height of smoke layer interface related with evacuation scenarios. (b) Temperature of smoke layer related with evacuation scenarios.

Fig. 10. Numerical results, 20 MW fire source, both-ends stairs on the center platform.

Figure 9a shows the plan and the location point of the both-ends stairways platform. Open stairways are provided at the edges of the platform. Widths of entrance of stairways are $1.5 \mathrm{~m}$ wide respectively. The occupant load, evacuation starting time and the time to clear platform are equal to center stairways platform. Scenarios of Smoke extraction fan and fire shutter in the platform are assumed to be the same as the center stairways platform. Figures $9 \mathrm{~b}-9 \mathrm{e}$ are summaries of calculation results for the both-ends stairways platform for the steady fire source. From the calculation results, the following observations can be pointed out: Temperature of smoke layer near the fire source generally exceeds 700 degree $C$ by steady fire source (Fig. 9c, point 6). Smoke extraction cannot lift the smoke layer interface in the middle position of the platform, which is far from the fire source (point 12, 15 and 18). It falls down to roughly $1.0 \mathrm{~m}$ with smoke extraction fan on. The temperature of smoke layer in the middle position of the platform rises up to 40-45 degree $C$ roughly. In the Both-ends stairways platform, beyond the half of the platform is exposed with smoke in spite of activation of the smoke extraction. However, temperature of smoke layer at distant from the fire, where the opposite side of platform is, hardly exceeds 30 degree C (point 21, 24, 27 and 30). Dilution by air lowers temperature of smoke at distant from the fire source.

The whole concourse is almost exposed with thin smoke almost when the shutters open (Figs. 9d, 9e). Smoke extraction cannot lift the smoke layer interface. Height of smoke layer interface falls down to $1.5-2.0 \mathrm{~m}$ far from the stairways to the platform and temperature of smoke rises up to about 40 degree $\mathrm{C}$ far from the stair in the concourse with shutters open and smoke extraction on (point 36, 37, 39 and 41). Height of smoke layer interface nearby the stair stays around $2.2 \mathrm{~m}$. However, temperature of smoke layer nearby the stairs exceeds 100 degree $C$ (point 40). Smoke is pulled up from the platform. Closure of shutter nearby the fire source and activation of smoke extraction lift the smoke layer interface up to $2.5 \mathrm{~m}$ approximately, and lower the temperature all over the concourse. Operation of the shutters affects significantly the smoke spread to concourse same as the center stairways platform.

Figures 10a, 10b are summaries of calculation results for the growing fire source; they can be described in connection with evacuation scenarios. After $40 \mathrm{sec}$ since the fire occurred, height of smoke layer interface falls down to $1.1 \mathrm{~m}$, and the smoke temperature rises up to about 100 degree $C$ nearby the fire source (point 6). It is hard to escape passing by the side of the fire source in a short time. While height of smoke layer 
interface a little away from the fire source falls down to $1.5 \mathrm{~m}$ after $140 \mathrm{sec}$ since the fire occurred, it is lifted up to about $2.5 \mathrm{~m}$ with smoke extraction fan activated. However, temperature of smoke rises up to 250-300 degree C after 300 sec since the fire occurred, consequently, radiative flux from the smoke layer may exceed the tolerance criteria to any people under the smoke layer, e.g., approximately $2.0 \mathrm{~kW} / \mathrm{m}^{2}$. Temperature rises in the lower air layer zone near the fire source can reach $10-30 \mathrm{~K}$, which together with the radiation from the smoke layer could torture evacuees in the vicinity of the fire (point 9). Height of smoke layer interface in the middle position of the platform fall down to $0.8 \mathrm{~m}$ after 300 sec since the fire occurred. Temperature of smoke layer rises up to over 50 degree $\mathrm{C}$ at the time to clear platform (point 12). Height of smoke layer interface far from the fire source, where the edge of platform is, stays at the height of $2.5 \mathrm{~m}$. Temperature of smoke layer maintains 25 degree C approximately (point 27, 30). While a severe fire occurs near a stairway, evacuees can evacuate from platform to concourse through another side of the stairway. Augmentation of smoke extraction would be indispensable to ensure safe evacuation, in order to get rid of thin smoke far from the fire source.

\section{CONCLUSIONS}

Although the experiments and the analyses conducted during the project are limited, the following findings can be useful for further researches and discussions for the safety of subway systems.

(1) Operation of fire shutters in the stairway has primary influence on the smoke movement. Closure of the shutters is generally beneficial not only for saving the concourse from smoke but also for keeping smoke layer on the platform level stable.

(2) Smoke movement and effectiveness of smoke control can be notably affected by the background air flow through the tunnel and outlets of the subway station.

(3) The numerical study by zone model and the experiments show good agreement in general for the conditions with shutters closed. However, considerable discrepancy can be seen for the conditions with shutters open.

(4) Smoke spread on the platform can be restricted within the fire area confined by the staircases and other obstacles.

(5) Temperature of smoke layer, unrelated to the smoke extraction, exceeds 700 degree $\mathrm{C}$ nearby the fire source and even up to 300 degree $\mathrm{C}$ rather far from the fire by a 20 MW fire. Even if appropriate operation of smoke extraction and so on may prevent evacuees from being trapped by smoke, high temperature smoke layer causes evacuation difficulty due to the exposure of evacuees to severe radiation. Evacuees must leave away from the fire source immediately.

(6) When a severe fire breaks out near a stairway, the stair will become to be unavailable for evacuation. And the whole concourse is almost clogged with thin smoke when the shutter nearby the fire is open. Operation of the shutters affects significantly the smoke spread to concourse. The shutters in stairways nearby the fire should be closed as soon as possible to prevent smoke rising up to concourse. This however means half of passengers are trapped by smoke at the Center stairs platform station. This shows general effectiveness of the provision of alternative evacuation routes on both ends of a platform.

(7) Restriction of the fire intensity is primarily important. If large scale fire occurred in the subway station, in which heat release rate exceeds 20 MW quickly, tragedy is 
unavoidable. Almost all of evacuees will be involved by high temperature smoke, even if the shutters and the smoke extraction fan are operated appropriately.

\section{ACKNOWLEGEMENT}

The experiment introduced in this report was conducted as a part of the Research Committee on the Underground Railway Systems organized by the Tokyo Fire Department (TFD) under the cooperation of Teito Rapid Transit Authority and Transportation Bureau of Tokyo Metropolitan Government. The authors would like to acknowledge cooperation of these organizations and the committee members. The authors are also indebted to Bin Du, Masayuki Hirota, Koji Kagiya, Fumikazu Kishimoto, Ken Matsuyama, Tsutomu Nagaoka, Masatoshi Nakamura, Taku Shimada, Keiichi Suzuki, Takashi Wakamatsu, Architecture Laboratory of Railway Technical Research Institute, TFD's Fire Science Laboratories, and members of Hasemi Lab. Waseda University, who helped greatly the experiments.

\section{REFERENCES}

[1] Hasemi, Y., Moriyama, S., Nam, D., Tanaka, S., Okazawa, N., and Ding, W., "Fire Safety Background for Japanese Underground Railway Systems and Field Experiments on The Smoke Movement in Subway Stations," Inter Science Communications -- Proceedings of the $10^{\text {th }}$ International Conference, INTERFLAM 2004, pp. 1563-1574.

[2] Hasemi, Y., Moriyama, S., Nam, D., Tanaka, S., Okazawa, N., Yonezawa, M., and Ding, W., "Research Needs on the Fire Safety of Subway Station -Fire disasters, Regulations, Research Efforts and Recent Smoke Movement Tests in Subway Stations in Japan,” Fire Science and Technology -- Proceedings of the $6^{\text {th }}$ Asia-Oceania Symposium for Fire Science and Technology, Daegue, Korea, March 2004, pp. 797-808.

[3] Tokyo Fire Department, "Report on Full Scale Experiments and Study on Railway Trains,” pp. 17-25, pp. 41-43, 1994 (in Japanese).

[4] Tokyo Fire Department, "Report of the Research Committee on the Fire Safety for Underground Railway Systems,” pp. 9-20, 2004 (in Japanese).

[5] Takei, Y., Yamada, S., Hayashi, A., Kamikawa, D., and Hasemi, Y., "Fire Behavior of a Large-Sized Kiosk in Railway Stations," Architectural Institute of Japan -- Summaries of Technical Papers of Annual Meeting, pp. 351-352, 2004 (in Japanese).

[6] The Building Center of Japan, Guideline of Building Safety Evacuation, pp. 128-139, 1995 (in Japanese).

[7] Tanaka, T., BRI2002 Two-Zone Model Based Code for the Prediction of Smoke Movement in Buildings, Association for the Promotion of Building Research, 2003 (in Japanese). 